\title{
The Application of Functional Equivalence Theory in English Translation of Science and Technology English
}

\author{
Baiping Huang \\ Pingxiang University, Pingxiang, Jiangxi, 337055, China
}

\begin{abstract}
Keywords: Functional equivalence theory; science and technology English; English translation
\end{abstract}
\begin{abstract}
In the translation of science and technology English, the theoretical connotation of functional equivalence is to transform the source language into the target language through translation. The science and technology English is a kind of professional English style, which contains a lot of technical and professional vocabulary. It is difficult to grasp the technical and professional vocabulary, and it needs to accurately describe the objective laws. The translator should apply it according to specific circumstances. Technology English language is accurate and concise, objective and rigorous. It is also with strong logic and professionalism, which also put forward higher demands on the translator. It is not only beneficial to the effective transmission and exchange of scientific and technological information, but also to help the translation of science and technology English better to serve the development and progress of science and technology.
\end{abstract}

\section{Introduction}

With the rapid development of globalization and the rapid development of science and technology, science and technology English translation in the international exchange plays an increasingly important role. And it extensively penetrates into the power, energy, industry, agriculture and other fields. It bears the dual task of introducing scientific and technological knowledge and information. Technology English has its own special technical vocabulary and complex syntactic structure [1-3]. The traditional translation, focusing on the lexical level, often only focuses on the text form of equivalence. It results in obscure text translation which is not conducive to the effective transmission and exchange of scientific and technological information.

Functional equivalence theory regards translation as a process of reconstructing information in two different coding environments. The semantic translation respects the semantic and syntactic structure of the original text and strives to reproduce the contextual meaning of the original text. It aims to make the target language readers to feel as close as possible to that of original reader's. Therefore, the translation of science and technology English is guided by the theory of functional equivalence, and also guided by the target language and its readers.

In the translation of science and technology English, the theoretical connotation of functional equivalence is to transform the source language into the target language through translation. The science and technology English is a kind of professional English style, which contains a lot of technical and professional vocabulary. It is difficult to grasp the technical and professional vocabulary, and it needs to accurately describe the objective laws. The translator should apply it according to specific circumstances. Technology English language is accurate and concise, objective and rigorous. It is also with strong logic and professionalism, which also put forward higher demands on the translator. It is not only beneficial to the effective transmission and exchange of scientific and technological information, but also to help the translation of science and technology English better to serve the development and progress of science and technology [4]. 


\section{Research on English for Science and Technology}

\subsection{Functional Translation Theory Overview}

In response to the influence of conversion grammar, Nida studied the translation process in an empirical way [5]. On the basis of formal equivalence, Nida further put forward the concept of functional equivalence, which focuses on the effect of the translation rather than the translation of vocabulary, grammar and structure. It believes that the translation is the exchange, and the response of target language readers is the key factors to evaluate the quality of the translated texts. Therefore, the translated texts to the target language readers should play the same role of the original text to the original reader. The functional equivalence of the translation regards the target language and its culture as a whole. It makes the information which needs to pass into the context of the target language. Nida points out that each language has a unique aspect which is different from other languages, such as sentence characteristics, chapter structure, etc. Effective translation can only be achieved on the basis of respect for language characteristics. For example, the English "I-type steel" can be translated into Chinese "工字钢" [6].

Nida further elaborates on the relationship between language and culture, and he thinks that language should not be an obstacle to cross-cultural communication. Language is part of a culture. In the process of translation, cultural differences weigh more than language differences. In order to achieve information transmission accuracy, the translator should take full account of cultural factors, rather than just stay in the language. For example, the Chinese "白象 (white elephant)" is translated as "docile cute" symbol, but in the West, it is used to refer to "big and useless, flashy" things. Therefore, to introduce "白象 " battery to the West, it needs to be translated as "silver elephant battery". Functional equivalence theory attempts to use scientific theory to explain the translation process and to promote the content-oriented reconstruction of the target language form so that the translation is more close to the target language culture. Thus it greatly enhances the readability of the translation.

\subsection{Classification of English for Science and Technology}

Science and Technology English, speaking from a broad sense, is English which is related to science and technology. Liu Yu points out that science and technology English refers to written and spoken language which is related to science and technology, including scientific and technical works, scientific research papers, reports and related experimental plans, various scientific and technological information, machinery and equipment description of the structure and the operation, technical questions, as well as audio and video materials such as film and video [7,8]. Reiss classify the English text of science and technology from the perspective of text type theory. He divides the text into three types: informative, expository and operative. So the text of science and technology English text is classified as information-based text which emphasizes the language of the external reality and authenticity.

\subsection{Vocabulary and Syntactic Features of Scientific English}

According to its meaning and function, science and technology English vocabulary can be divided into two categories: professional and technical vocabulary and semi-professional technical vocabulary. This is one of the most striking features of technological English, which can directly and objectively describe the concept of science and technology. Such as telecommunications (通信) and microwave (微波) are professional and technical vocabulary in the field of electronic and microelectronics. Pyramid (金字塔形, 雉形) and refrigeration (制冷) are semi-professional technical vocabulary, because they are derived from the general English vocabulary, which exists with attaching to a certain contextual meaning in the field of electronic and microelectronics. Extensive use of acronyms is also a major feature of technology English, such as ISO (International Standardization Organization) and IC (Integrated Circuit). In order to avoid narrative with subjective 
color, science and technology English uses more nominal structure, passive statements, non-predicate verbs and long sentences, in order to highlight the description of the objectivity and logic. Such as:

(a) With the continuing improvement in transportation and distribution networks, wind turbine, the new electricity -generating technology, are of great importance. data.

(b)A wide knowledge of statistics is required by the scientists for the detailed analysis of the

(c)Compared with other types of machines, this one is small, quiet, smooth running and easily controlled.

Example sentence (a) uses the nominal structure to highlight the style of science and technology English text concise style, and emphasize the existence of the facts. So that the expression is more objective, and the content is more accurate and more authoritative. Example sentence (b) uses passive voice to avoid the first and second person bringing the subjective assumptions. The use of third person narrative grasps the key information easily, but also stresses the objectivity and rigor of information. Example sentence (c) replaces the clause with the word phrase, which not only makes the sentence concise, writing compact, but also is in line with the technical translation of the characteristics of information transmission.

\section{Function Relatively Equivalent}

Western translation theory although has all kinds of translation factions, but the dominant position is still the core concept of equivalence theory. Translation equivalence theory also advocates as far as possible the most natural translation of the language, which is the most close to the original meaning. That is not absolute, but relative, which can not be completely equal.

\subsection{Relativity of Form Equivalence}

Functional equivalence theory emphasizes on the translation of the form of reciprocity, mainly voice, vocabulary, grammar and other concepts of relative reciprocity. These words are the specific manifestations which form in a long time cultural differences.

Table 1. Examples of vocabulary unequal

\begin{tabular}{ll}
\hline Chinese & English \\
\hline 兵工厂 & arsenal \\
原子能发电厂 & Atomic power plant \\
汽车厂 & car factory \\
化工设备厂 & Chemical equipment factory \\
冶炼厂 & Smelter \\
棉纺厂 & Cotton mill \\
铸造厂 & foundry \\
啤酒厂 & Brewery \\
陶器厂 & Pottery factory \\
制药厂 & Pharmaceutical factory \\
秘密制药厂 & Clandestine laboratories \\
\hline
\end{tabular}

As shown in Table 1, the Chinese term has the "厂" morpheme, but the corresponding English has plant, factory, works, mill, laboratory and other words.

\subsection{Relativity of Functional Equivalence}

Functional equivalence emphasizes that language and culture can communicate through the search for translation equivalents, and reorganize the information forms and semantic structures. The purpose of the language in a different language structure is as much as possible to reproduce the 
meaning of the source language. In the concrete process of translating science and technology English into Chinese, all equivalent transformations should be carried out on each pair of the corresponding ranks and levels, and functional equivalence is accordingly established on those planes. It is evidently a complicated process. To make things clear, Table 2 can be employed which is shown as follows:

Table 2. Equivalence on different ranks and levels of language

\begin{tabular}{|l|l|l|l|l|l|}
\hline \multicolumn{2}{|c|}{} & \multicolumn{3}{|l|}{ Rank } \\
\cline { 3 - 6 } \multicolumn{2}{|c|}{} & $\begin{array}{l}\text { Word } \\
\text { equivalence }\end{array}$ & $\begin{array}{l}\text { Phrase } \\
\text { equivalence }\end{array}$ & $\begin{array}{l}\text { Sentence } \\
\text { equivalence }\end{array}$ & $\begin{array}{l}\text { Discourse } \\
\text { equivalence }\end{array}$ \\
\hline \multirow{4}{*}{ Level } & $\begin{array}{l}\text { Deep } \\
\text { level }\end{array}$ & $\begin{array}{l}\text { Word } \\
\text { deep-level } \\
\text { equivalence }\end{array}$ & $\begin{array}{l}\text { Phrase } \\
\text { deep-level } \\
\text { equivalence }\end{array}$ & $\begin{array}{l}\text { Sentence } \\
\text { deep-level } \\
\text { equivalence }\end{array}$ & $\begin{array}{l}\text { Discourse } \\
\text { deep-level } \\
\text { equivalence }\end{array}$ \\
\cline { 2 - 6 } & $\begin{array}{l}\text { Rhetoric } \\
\text { level }\end{array}$ & $\begin{array}{l}\text { Word } \\
\text { rhetoric-leve } \\
\text { lequivalence }\end{array}$ & $\begin{array}{l}\text { Phrase } \\
\text { rhetoric-leve } \\
\text { lequivalence }\end{array}$ & $\begin{array}{l}\text { Sentence } \\
\text { rhetoric-leve } \\
\text { 1 equivalence }\end{array}$ & $\begin{array}{l}\text { Discourse } \\
\text { rhetoric-leve } \\
\text { 1 equivalence }\end{array}$ \\
\cline { 2 - 6 } & $\begin{array}{l}\text { Surface } \\
\text { level }\end{array}$ & $\begin{array}{l}\text { Word } \\
\text { surface-level } \\
\text { equivalence }\end{array}$ & $\begin{array}{l}\text { Phrase } \\
\text { surface-level } \\
\text { equivalence }\end{array}$ & $\begin{array}{l}\text { Sentence } \\
\text { surface-level } \\
\text { equivalence }\end{array}$ & $\begin{array}{l}\text { Discourse } \\
\text { surface-level } \\
\text { equivalence }\end{array}$ \\
\hline
\end{tabular}

But in fact, the difference between language and culture is tremendous. The level of development of science and technology is also very uneven. It must be only self-defeating if people want to find the translation of the function of the absolute reciprocity. For example: black tea translated as "红茶" rather than "黑茶". Here, we need to overcome cultural differences and translate the meaning of their expression so that the translation can maintain the function of the relative reciprocity.

\section{Summary}

The English translation of science and technology holds the dual purpose of transmitting scientific and technological information and enhancing academic exchange and scientific development. The objectivity and logic of the science and technology English determine to adopt appropriate translation method when translating. Functional equivalence translation theory advocates the emphasis on the needs of target readers in translation, and tries to reproduce the information of the original text with the closest and most natural equivalents. Therefore, it has a positive guiding role in the translation of science and technology. In the translation, translators should pay attention to the information function of science and technology English. And also translators should strive to meet the technical norms of accurate translation, and to ensure the accuracy and truth of the information. In addition, translators should have a certain background knowledge and cultural heritage. Translators should make the effective use of science and technology in English embodied in interpersonal relationship so to achieve the purpose of better conveyance of scientific and technical information to readers of target language.

\section{Acknowledgement}

This work is supported by Social Science Project of Jiangxi Province (13WX321).

\section{References}

[1] Zhu J T. On Business English Translation from the Perspective of Functional Equivalence Theory [J]. Journal of Hubei Correspondence University, 2016.

[2] Tang J. Based on the Functional Equivalence Theory to explore the Business English Translation [J]. Overseas English, 2016. 
[3] Zhang S, Sun H Y, University M N. Business English translation on the perspective of functional equivalence theory [J]. Heilongjiang Science, 2016.

[4] Niu T. On English Film Title Translation from the Perspective of Functional Equivalence Theory [J]. Guide of Science \& Education, 2014.

[5] Ya-Fei M A. Business English Translation Studies under the Theory of Functional Equivalence [J]. Overseas English, 2016.

[6] Shi R F. Impact of Functional Equivalence Theory in the Translation of Metaphors — - Take Fortress Besieged as an Example [J]. Journal of Shanxi Datong University, 2014.

[7] Ren Q. On the Translation Techniques of Chinese Political Essays from the Perspective of Nida s Functional Equivalence Theory Taking the Report to the 18th National Congress of the CPC as Corpus[C]// International Conference on Education, Language, Art and Intercultural Communication. 2014.

[8] Shi X. Chinese-English Translation Strategies of Public Signs Based on Functional Equivalence Theory [J]. Journal of Language Teaching \& Research, 2014, 5 (4). 